Original Article

\title{
FORMULATION AND IN VITRO EVALUATION OF POLY-HERBAL ANTI-AGEING FACE CREAM OF CORIANDRUM SATIVUM AND ROSE HIP OIL
}

\author{
ARSHAD AYUB AHMED ${ }^{1}$, BIPUL NATH ${ }^{2}$ \\ ${ }^{1}$ Girijananda Chowdhury Institute of Pharmaceutical Science, Azara, Hatkhowapara, Guwahati-17, ${ }^{2}$ Depertment of Pharmaceutical \\ Science, Girijananda Chowdhury Institute of Pharmaceutical Science, Azara, Hatkhowapara, Guwahati-17 \\ Email: arshad.ayub.ahmed@gmail.com
}

Received: 28 Jan 2017, Revised and Accepted: 20 Apr 2017

\begin{abstract}
Objective: The purpose of this study was to develop anti-ageing poly-herbal face cream by mixing the ethanol extract of C. sativum and rose hip oil in order to produce multipurpose effects on the skin such as fairness, softening and antiseptic effects.

Methods: Ageing of the skin is the result of continuous "wear and tear" processes. Chronological skin aging is a universal and inevitable process, while in contrast, photoaging results from the UV rays of sunlight, and the damage becomes apparent in sun-exposed skin. Cream is defined as semisolid emulsions which may be oil-in-water $(\mathrm{o} / \mathrm{w})$ or water-in-oil (w/o) type and these semisolid emulsions are meant for external applications. In this study creams (o/w type) were formulated based on the anti-oxidant potential of herbal extracts and its evaluation. Coriandrum sativum plant extracted by using soxhlet method with water as solvent. The creams were formulated with coriander oil, rose hip oil with different concentrations namely F1 to F6.
\end{abstract}

Results: The creams were to be stable during stability studies accordingly ICH guideline for 2 mo. Coriandrum sativum extract showed significant anti-oxidant activity with an IC 50 value is $34.25 \mu \mathrm{g} / \mathrm{ml}$, while for ascorbic acid the IC $C_{50}$ value was $46.68 \mu \mathrm{g} / \mathrm{ml}$.

Conclusion: It can be concluded that herbal creams without side effects having antioxidant property can be used as provision of a barrier to protect the skin and avoid aging of the skin.

Keywords: Anti-aging, Poly Herbal cream, Anti-oxidant, Extraction

(C) 2017 The Authors. Published by Innovare Academic Sciences Pvt Ltd. This is an open access article under the CC BY license (http://creativecommons.org/licenses/by/4.0/) DOI: http://dx.doi.org/10.22159/ijcpr.2017v9i4.20961

\section{INTRODUCTION}

Ageing is the changes in a person associated with physical, psychological, mental and social change. Aspects like knowledge, experience and wisdom may increase while reaction time, memory etc. may decline. Older population increases both in the developed and developing nations due to the medical facility [1-3].

Anti-ageing means holding back the signs of ageing on our skinpreventing or reducing the appearance of wrinkles, firming up the skin and dealing with uneven skin tone or age spots. Ultimately, anti-ageing is about looking younger and finding that elusive skincare fountain of youth. Anti-aging is possible when the process of regeneration dominant over degeneration. In the case of regeneration, the cells replace itself with stronger cells while in degeneration, existing replace with weaker one. The process of regeneration is termed as anti-aging while the process of degeneration is called as ageing [2,3].

The cream is defined as semisolid emulsions which are oil-in-water $(\mathrm{o} / \mathrm{w})$ or water-in-oil (w/o) type and these semisolid emulsions are intended for external applications. Creams are often composed of two phases. Oil-in-water $(\mathrm{o} / \mathrm{w})$ emulsions are most useful as waterwashable bases, whereas water-in-oil (w/o) emulsions are emollient and cleansing agents. An emulsifying agent is used to disperse the aqueous phase in the oily phase or vice versa $[1,4]$.

World Health Organization (WHO) as well our country has been promoting traditional medicine because they are less expensive, easily available and comprehensive, especially in developing countries. It is also true that eight percent of the world's population relies on medicinal plants for their primary health care. The whole world including the developed country recognized the importance of traditional medicine and has treatment strategies, guidelines and standard for ethnomedicine [2].

Coriander (Coriandrum sativum L.) which belongs to the family Apiaceae (Umbelliferae) is mainly cultivated from its seeds throughout the year. All parts of this herb are in use as a flavouring agent and/or as traditional remedies for the treatment of different disorders in the folk medicine systems of different civilisations. It mostly contains essential oil and fatty oil. The rosehip seed oil (RHO) is extracted from the seed of the fruit of the wild plants of Rosa species such as Rosa canina, Rosa rubiginosa, Rosa moschata belonging to the family Rosaceae. It contains polyunsaturated fatty acid especially linoleic acid (54\%), linolenic acid (17\%) and oleic acid (16\%) between others [2-5].

Although various types of cream is considered for anti-ageing these still appear to be limited in rate of tissue regeneration. Hence after a depth review regarding pathogenesis as well as different traditional and alternative treatment for anti-ageing, we have taken up the project to develop and formulate a herbal cream which will be effective and has a better rate of effectiveness for anti-ageing. The herbal cream that is planned to be formulated for anti-ageing will be oil/water $(\mathrm{O} / \mathrm{W})$ emulsion type which will be less oily, less greasy and less sticky in nature so that patient compliance is more and will be beneficial for all kind of people in our society $[2,4,6]$.

After thorough review, we have selected following herbs to formulate the cream for anti-ageing action-

$>$ Coriander oil (antioxidant property)

$>$ Rose hip oil (rich source of vitamin C)

In this, we have made an attempt to formulate most complete herbal cream that contains herbs which will satisfy almost all the mechanism of anti-ageing activity effectively $[2,6,7]$.

\section{MATERIALS AND METHODS}

\section{Materials}

Collection of plant materials

The fresh plants of Coriandrum sativum were collected from the local market of Kamrup, Assam; and the oil was extracted by Clevenger apparatus. Rose hip oil was collected from ARAMACS Brand, Delhi. 


\section{Chemicals and reagents}

The chemicals used during the experiments were of analytical grade. Lanolin (Burgoyne Urbidges and Co), White petrolatum (Yarrowchem Products), Tween 60, Stearic acid (Himedia Lab), Mineral oil, Triethanolamine, Propylene Glycol (Merck Lab), Betadine; Povidoneiodine IP 5\% w/w, (Win-Medicare) etc were used.

\section{Instruments}

Clevenger Apparatus, Homogenizer, Centrifuge (REMI), Viscometer (Brookfield DV-E viscometer), Digital Balance (Denver Instrument), Digital pH meter (Systronics) etc. were used.

\section{Methods}

\section{Extraction of plant materials}

The extractions of crude drugs were carried out by Simple distillation method using water (aqueous extract) by the clavenger apparatus. The plant was washed and placed in the RBF. The extraction process was performed for $6 \mathrm{~h}$ and the extract was collected $[6,7]$.

\section{Antioxidant activity of C. sativum}

The anti-oxidant activity was carried out by mixing $1.5 \mathrm{ml}$ of the oil with $2.0 \mathrm{ml}$ of a. $02 \mathrm{M}$ methanolic2, 2-Diphenyl-1- picrylhydrazyl (DPPH) solution at three final concentrations (5, 25 and $100 \mathrm{mg}$ oil $/ \mathrm{ml}$ ). The mixture was then incubated in the dark for $30 \mathrm{~min}$ at $25{ }^{\circ} \mathrm{C}$ and the absorbance at $517 \mathrm{~nm}$ was recorded as (A sample), using Spectrophotometer. A blank experiment was also carried out applying the same procedure to a solution without the test material and the absorbance was recorded as (Ablank). The scavenging activity of each solution was then calculated as percent inhibition according to the following equation: $[7,8]$

$$
\% \text { Inhibition }=\left[\left(\text { Ablank}_{\text {b }} \mathrm{A}_{\text {sample }}\right) / \mathrm{Ablank}\right] \mathrm{X} 100
$$

\section{Formulation of herbal cream $(0 / \mathrm{W}$ emulsion)}

Ingredient of the oil phase (A) was melted in a beaker by using a water bath on constant stirring. Components of aqueous phase (B) were mixed together and warmed to about the same temperature of oil phase (up to $70^{\circ} \mathrm{C}$ ). The preservative methylparaben and concentrated aqueous extract of the plants were added into an aqueous phase and heated. Then oil phase was added to water phase little by little on constant stirring and perfume was added to it when the temperature was $35{ }^{\circ} \mathrm{C}-40{ }^{\circ} \mathrm{C}$. Six different formulations (F1-F6) were prepared by using varying concentration of the aqueous extract, stearic acid and liquid paraffin. The formula for the cream is given in table $1[2,9]$.

Table 1: Composition of $C$. sativum and rose hip oil based face cream

\begin{tabular}{|c|c|c|c|c|c|c|}
\hline \multirow[t]{2}{*}{ Ingredients } & \multicolumn{6}{|c|}{ Formulation code $(\% \mathrm{w} / \mathrm{w})$} \\
\hline & F1 & F2 & F3 & F4 & F5 & F6 \\
\hline Aq. Extract of Coriandrum sativum & 2 & 2.5 & 3.0 & 3.5 & 4.0 & 5.0 \\
\hline Rose hip oil & 1.0 & 1.5 & 2.0 & 2.5 & 3.0 & 3.5 \\
\hline Liquid paraffin & 14 & 13.5 & 11.0 & 10.0 & 8.5 & 7.5 \\
\hline Lanolin & 0.8 & 0.8 & 0.8 & 0.8 & 0.8 & 0.8 \\
\hline Stearic acid & 10 & 11.0 & 12.0 & 13.5 & 14.5 & 15.5 \\
\hline Cetyl alcohol & - & 0.5 & 0.5 & 1.5 & 1.5 & 2.0 \\
\hline Propylene glycol & 2.5 & 2.5 & 2.5 & 3.0 & 3.0 & 3.0 \\
\hline Glycerine & 4 & 4 & 4 & 4 & 4 & 4 \\
\hline Triethanolamine & 1 & 1 & 1 & 1 & 1 & 1 \\
\hline Tween 60 & 5.0 & 5.0 & 5.0 & 5.0 & 5.0 & 5.0 \\
\hline Methyl paraben & 0.1 & 0.1 & 0.1 & 0.1 & 0.1 & 0.1 \\
\hline Water & g. $s$ & g. $s$ & g. $s$ & g. $s$ & g. $s$ & g. $s$ \\
\hline
\end{tabular}

\section{Evaluation of cream}

The formulations or creams were evaluated for different pharmaceutical parameters as follows_

\section{Type of emulsion}

A portion of the product was taken in a watch glass. To that water soluble dye (methylene blue) was added, mixed properly and observed under the microscope the dispersed oil globules in the colored aqueous phase (Dye method). Fixed amount of cream was diluted with water and mineral oil separately. Then they are observed for separation of both the phases in oil and water (Dilution method) $[9,10]$.

\section{Organoleptic evaluation}

The prepared cream was evaluated for its organoleptic properties like color, odor, physical state, appearance, roughness etc $[2,12,13]$.

\section{pH of the cream}

The $\mathrm{pH}$ meter was calibrated using standard buffer solution. About $0.5 \mathrm{~g}$ of cream was weighed and dissolved in $50.0 \mathrm{ml}$ of distilled water and its $\mathrm{pH}$ was measured $[7,12]$.

\section{Homogeneity}

The formulations were tested for the homogeneity by visual appearance and by touch $[2,12,13]$

\section{After feel}

Emolliency, slipperiness and amount of residue left after the application of fixed amount of cream was checked $[2,12,13]$

\section{Removal}

The ease of removal of the cream applied was examined by washing the applied part with tap water $[2,12,13]$

\section{Accelerated stability of cream}

The accelerated stability studies of formulated cream were carried out at $40{ }^{\circ} \mathrm{C} / 75 \% \mathrm{RH}$ for $1 \mathrm{mo}$. The effects of temperature, humidity and time on the physical characteristics creams were evaluated for assessing the stability of the prepared of the formulations. The stability studies were out when the room temperature was $20^{\circ}$ to $25{ }^{\circ} \mathrm{C}$. The $\mathrm{pH}$, viscosity, spreadability and phase separation in 10 and 40 min centrifugation were evaluated for stability after keeping for 1 mo [12-16].

\section{Viscosity}

The viscosity of the formulation was determined by Brookfield Viscometer. The viscosity measurements were done using Brookfield DV-II+viscometer using 64 spindles. The developed formulation was poured into the adaptor of the viscometer and the viscosity measured at different spindle speed from 0.5 to $100 \mathrm{rpm}$ $[2,12,15]$. 
Table 2: Accelerated stability study of cream formulations

\begin{tabular}{|c|c|c|c|c|c|c|c|c|}
\hline \multirow[t]{2}{*}{ No of days } & \multirow[t]{2}{*}{ Temp. $\left({ }^{\circ} \mathrm{C}\right)$} & \multirow[t]{2}{*}{ Form. code } & \multicolumn{6}{|c|}{ Assessment parameters } \\
\hline & & & pH & Homo genicity & Appearance & Spreadability & After feel effect & Ease of remove \\
\hline \multirow[t]{2}{*}{0} & RT & F4 & 6.33 & $\mathrm{G}$ & $\mathrm{NC}$ & $\mathrm{G}$ & $\mathrm{E}$ & $\mathrm{Y}$ \\
\hline & Acc. & F5 & 6.36 & $\mathrm{G}$ & NC & $\mathrm{G}$ & $\mathrm{E}$ & $\mathrm{Y}$ \\
\hline \multirow[t]{2}{*}{10} & RT & $\mathrm{F} 4$ & 6.39 & $\mathrm{G}$ & NC & $\mathrm{G}$ & $\mathrm{E}$ & $\mathrm{Y}$ \\
\hline & Acc. & F5 & 6.44 & $\mathrm{G}$ & NC & $\mathrm{G}$ & $\mathrm{E}$ & $\mathrm{Y}$ \\
\hline \multirow[t]{2}{*}{15} & RT & F4 & 6.45 & $\mathrm{G}$ & NC & $\mathrm{G}$ & $\mathrm{E}$ & $\mathrm{Y}$ \\
\hline & Acc. & F5 & 6.48 & $\mathrm{G}$ & NC & $\mathrm{G}$ & $\mathrm{E}$ & $\mathrm{Y}$ \\
\hline \multirow[t]{2}{*}{20} & $\mathrm{RT}$ & F4 & 6.51 & $\mathrm{G}$ & NC & $\mathrm{G}$ & $\mathrm{E}$ & $\mathrm{Y}$ \\
\hline & Acc. & F5 & 6.55 & $\mathrm{G}$ & NC & $\mathrm{G}$ & $\mathrm{E}$ & $\mathrm{Y}$ \\
\hline \multirow[t]{2}{*}{30} & RT & F4 & 6.56 & $\mathrm{G}$ & NC & $\mathrm{G}$ & $\mathrm{E}$ & Y \\
\hline & Acc. & F5 & 6.59 & $\mathrm{G}$ & NC & $\mathrm{G}$ & $\mathrm{E}$ & $\mathrm{Y}$ \\
\hline
\end{tabular}

RT-Room Temperature, G-Good, NC-No Change, E-Emollient, Y-Yes

\section{Skin irritation test}

The cream was evaluated for primary skin irritation test on experimental animals (shaved back of the mice) to evaluate the safety of cream. The experiment was conducted in accordance to the protocol approved by Institute Animal Ethics Committee (IAEC), Girijananda Chowdhury Institute of Pharmaceutical sciences. Guwahati, Assam. (Approval no-GIPS/IAEC/B. Ph/2017/20) [2, 16, 17].

\section{RESULTS}

\section{Antioxidant activity}

In the present study, the total antioxidant activity of aqueous plant extract was found as IC $\mathrm{I}_{50}$ value is $34.25 \mu \mathrm{g} / \mathrm{ml}$ while for ascorbic acid $\mathrm{IC}_{50}$ was $46.68 \mu \mathrm{g} / \mathrm{ml}$.

\section{Skin irritation test}

The formulation F4and F5 shows no redness, edema, inflammation and irritation during irritancy studies. These formulations are safe to use for skin.

\section{pH of the cream}

The $\mathrm{pH}$ of the cream was found to be in the range of 5.6 to 6.8 which is good for skin $\mathrm{pH}$. All the formulations of cream were shown $\mathrm{pH}$ nearer to skin required i.e. pH of F1-5.8, F2-6.0, F3-6.5, F4-6.33, F5-6.36 and F6-6.8

\section{Viscosity}

The viscosity of cream was in the range of 500-1500 cps which indicates that the cream is easily spreadable by small amounts of shear. F4 and F5 show good spreadable property than other formulations.

\section{Homogeneity}

All formulations produce a uniform distribution of extracts in cream. This was confirmed by visual appearance and by touch.

\section{After feel}

Emolliency, slipperiness and amount of residue left after the application of fixed amount of cream was found good.

\section{Removal}

The cream of F4 and F5 applied on skin was easily removed by washing with tap water

\section{Appearance}

When formulation was kept for a long time, it found that no change in color of cream.

\section{Selection of formulation}

From the above study, we have selected the best formulation on the basis of physical stability and the desired percentage of active ingredients. The formulation that was taken for further pharmacological evaluation was formulation 5 (F5).

\section{CONCLUSION}

From above results, it is concluded that on combining the extracts of Coriandrum sativum and rose hip oil different components in a different ratio to get multipurpose effect such as anti-wrinkle, antiaging and sunscreen effect on the skin. This activity may be mainly due to free radical scavenging, antioxidant activity of the extract also reported to supplying vitamin $\mathrm{C}$ which promoting tissue regeneration. The research work suggests that the herbal antioxidant formulation and its ingredients were studied to be consistent in quality and purity and can be easily used as a face cream. The validation of the cream was done and was found in limits. From above discussion, it is concluded that the formulation F4 and F5 are safe usable for the skin. This study can be helpful for upcoming researchers to select these herbs for the formulation and evaluation of other cosmetic applications which can be claimed for their efficacy with scientific data.

\section{CONFLICT OF INTERESTS}

Declare none

\section{REFERENCES}

1. Yuko S, Akihiko S. Establishment of an anti-aging health screening service in an obstetrics and gynaecology department of a public hospital. Anti Aging Med 2013:10:6-111.

2. Das T, Debnath J, Nath B, Dash S. Formulation and evaluation of a herbal cream for wound healing activity. Int J Pharm Pharm Sci 2014;6:693-7.

3. Alfredo G, Sarita MC, Veronica C, Samuel MRN, Silvana AACN, Lydia MF. Review of major theories of skin ageing. Adv Aging Res 2014;3:265-84.

4. Bhumika S, Arvind S. Future prospect of nanotechnology in the development of anti-ageing formulations. Int J Pharm Pharm Sci 2012;4:57-66.

5. Clarence T Ueda (Chair), Vinod P Shah (USP Scientific Liaison). Topical and transdermal drug products. Pharmacopeial Forum 2009;35:750-64.

6. Surya PM, Santhosh AM, Gulshan MD, Raghavamma STV, Rama RN. Formulation and evaluation of anti-aging polyherbal cream. Int J Pharm Sci Rev Res 2014;24:133-6.

7. Ravichandran G, Derm M, Shivaram B, Dip NB. Evaluation of the efficacy and safety of 'Anti-Wrinkle cream' in the treatment of facial skin wrinkles. A prospective, open, phase III clinical trial. Antiseptic 2005;102:75-70.

8. Mayank Gangwar, Manish Kumar Gautam, Amit Kumar Sharma, Yamini B Tripathi, RK Goel, Gopal Nath. Antioxidant capacity and radical scavenging effect of polyphenol-rich mallotusphilippenensis fruit extract on human erythrocytes: an in vitro study. Sci World J 2014. http://dx.doi.org/10.1155/ $2014 / 279451$.

9. Ruiz MA, Clares B, Morales ME, Gallardo V. Evaluation of the anti-wrinkle efficacy of cosmetic formulations with an antiaging peptide (Argireline). ARS Pharm 2010;50:168-76. 
10. Sujith SN, Molly M, Sreena K. Formulation and evaluation of herbal cream containing curcuma longa. Int J Pharm Chem Sci 2012;1:1362-8.

11. Duraivel S, Asma S, Rabbani B, Eesaf P, Jilani. Formulation and evaluation of antiwrinkle activity of cream and nanoemulsion of moringaoleifera seed oil. IOSR J Pharm Biol Sci 2014; 9:58-73.

12. Indian Pharmacopoeia: Ministry of Health and Family Welfare, Government of India. Published by the Indian Pharmacopoeial commission: Ghaziabad; 2010.

13. United States Pharmacopoeia. The US pharmacopoeial convention. $35^{\text {th }}$ edn. Inc.12601 Twinbrook Parkway, Rockville MD20852; 2007.

14. Sheraz MA, Ahmed S, Ahmad I, Shaikh RH, Vaid FHM, Iqbal K. Formulation and stability of ascorbic acid in topical preparations. Syst Rev Pharm 2011;2:86-90.
15. Singhal M, Khanna S, Nasa A. Cosmeceuticals for the skin. Asian J Pharm Clin Res 2011;4:1-6.

16. Akash S, Mali, Karekar P, Yadav AV. Formulation and evaluation of multipurpose herbal cream. Int J Sci Res 2015;4:1495-8.

17. S Bhat, $\mathrm{P}$ Kaushal, $\mathrm{M}$ Kaur, HK Sharma. Coriander (Coriandrumsativum L.) processing, nutritional and functional aspects. Acad J 2014;8:25-33.

How to cite this article

- $\quad$ Arshad Ayub Ahmed, Bipul Nath. Formulation and in vitro evaluation of polyherbal anti-ageing face cream of coriandrum sativum and rose hip oil. Int J Curr Pharm Res 2017;9(4):75-78. 